\title{
Intrathecal Administration of Flavopiridol Promotes Regeneration in Experimental Model of Spinal Cord Injury
}

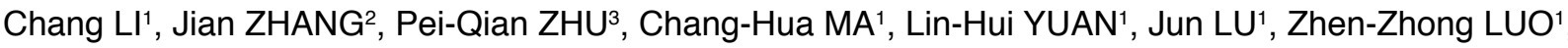 \\ Guo-Hai XU1 \\ 'Second Affiliated Hospital of Nanchang University, Department of Anesthesiology, Nanchang 330006, China \\ ${ }^{2}$ Nanjing Medical University, Huai'an First People's Hospital, Department of General Surgery, Huai'an 223300, China \\ ${ }^{3}$ Second Affiliated Hospital of Nanchang University, Department of General Surgery, Nanchang 330006, China
}

\section{ABSTRACT}

AIM: Spinal cord injury (SCl) is a serious condition of the central nervous system and it affects the quality of life and even hampers the day-to-day activity of the patient. In the current study, we investigated the efficacy of intrathecal administration of flavopiridol in an experimental animal model of SCl. The study also aimed at exploring the physiological effects of flavopiridol on neurons, astrocytes and cell cycle regulatory proteins.

MATERIAL and METHODS: In vitro scratch wound experiments were performed on female Sprague-Dawley rats ( $\mathrm{n}=23$ ). A complete hemisection to the right of T10 was made, and flavopiridol solution ( $200 \mathrm{mM}, 0.8 \mathrm{nmol}$ flavopiridol/animal) was delivered topically to the lesion site. Cell viability assay, in vitro scratch injury assay, cell cycle analysis using flow cytometry and behavioural assessments were performed.

RESULTS: The local delivery of flavopiridol reduced cavity formation and improved regeneration of neurons with improvement in physiological performance. Flavopiridol also inhibited the migration and proliferation of astrocytes, and at the same time, promoted the survival of neurons.

CONCLUSION: Intrathecal administration of flavopiridol can be a promising treatment strategy in patients with SCI and it needs to be validated in patient setting.

KEYWORDS: Spinal cord injury, Intrathecal injections, Flavopiridol

\section{INTRODUCTION}

0 pinal cord injury (SCl) is a debilitating condition of the central nervous system that has a detrimental effect on the quality of life of a patient. The global estimated annual incidence of $\mathrm{SCl}$ is about 50 per 1 million people (1). The sudden loss of sensory, motor and autonomic function severely hampers the day-to-day activity of a person. Currently, there are limited treatment options, and a majority of them are restricted to surgery, minimising secondary impediment and rehabilitation. Owing to the limited recovery of neurons and neurological dysfunction, the patient is often left with lifelong disability (24). In spite of substantial efforts in research on finding the therapeutic cure, only limited treatment or rehabilitation strategies are currently available for the patients.

Various experimental models have shown upregulation of molecules associated with cell cycle, such as cyclin G1, cyclin D1 (ccnd1), E2F1 and proliferating cell nuclear antigen (pcna) in the pathophysiology of SCI. Downregulation of endogenous cyclin-dependent kinase (CDK) inhibitor, p27, has also been reported $(7,44)$. In various animal models of SCI $(39,41,44)$, brain injury $(8,17)$ and cerebral ischaemia $(40,42)$, pathological activation of the cell cycle has been shown to cause neuronal 
cell death, and at the same time, to trigger mitotic cell activation and proliferation. CDK inhibitors have been widely studied for their role in cell cycle regulation (22). Flavopiridol is one such nonselective CDK inhibitor that reduces the mRNA transcription of cyclin D1 and arrests the cell cycle at G1 or G2/M transition stage $(23,36)$.

Various studies have indicated that flavopiridol, when administered intraperitoneally, can significantly improve neuronal function, reduce lesion volume, induce motor recovery, decrease astrocyte reactivity and prevent neuronal apoptosis after SCI (44). Owing to its broad-spectrum inhibitory activity, administration of a high systemic dose of flavopiridol may cause significant side effects $(16,31)$. Previous studies have only reported that flavopiridol reduces the expression of microglia-associated proteins (5); however, the effects of flavopiridol on other cell types, such as astrocytes, remain unclear. Certain devices, such as miniosmotic pumps $(5,16,31)$, that are used for intrathecal delivery are quite expensive and suffer from histocompatibility issues because of the material used in the manufacturing of the pumps. In the current study, we evaluated a simple method for intrathecal administration of flavopiridol and investigated its neuronal regeneration activity in a rat model of SCl. We also aimed at addressing the lacuna in the understanding of the mechanism of action of flavopiridol in the recovery of $\mathrm{SCl}$ before it can be used in clinical practice.

\section{MATERIAL and METHODS}

\section{Primary Cell Culture}

Purified astrocyte cultures from embryonic day 20 (E20) to postnatal day 1 (P1) Sprague-Dawley rats were prepared as per the standard protocol $(14,32)$. The animals were anaesthetised with $10 \%$ chloral hydrate and killed as per the Guidelines for the Care and Use of Laboratory Animals. Cortices were cut, dissociated and plated in a high-glucose Dulbecco's modified Eagle's medium (DMEM) containing $10 \%$ fetal bovine serum (FBS, Gibco) and $2 \mathrm{mM}$ glutamine. The medium was completely changed after $24 \mathrm{~h}$, and the cells were cultured for 10 days with complete medium passages after every $48 \mathrm{~h}$.

We obtained cortical neurons from cortices of P1-P3 rats according to the method described previously $(15,37,38)$. Briefly, the neurons were preplated on Petri plates in complete DMEM media for $2 \mathrm{~h}$ for purification. The cells were then collected by centrifugation and the pellet was resuspended in neurobasal medium supplemented with $2 \mathrm{mM}$ glutamine, $2 \%$ B27 and 1\% penicillin or streptomycin in 6-well plates (Invitrogen, USA). RNA was extracted from the 6-well plates, and cell viability assay was performed in 96-well plates. RNA isolation and real-time polymerase chain reaction (PCR) were performed as per the standard protocol to evaluate the effects of flavopiridol on cell cycle.

\section{Cell Viability Assay}

The viability and proliferation of astrocytes and neurons were measured using a commercially available CCK-8 Cell Counting kit (Dojindo Laboratories, Kumamoto, Japan).
The cultured cells were treated with different concentrations of flavopiridol (Shanghai Haoyuan Chemexpress, China). As per the manufacturer's protocol, the cells were then incubated in CCK-8 solution in a $5 \% \mathrm{CO}_{2}$ incubator at $37^{\circ} \mathrm{C}$ for $2 \mathrm{~h}$ as per the time point. The cell number was determined by measuring the absorbance at $450 \mathrm{~nm}$, with the reference wavelength at $650 \mathrm{~nm}(45)$.

\section{In Vitro Scratch Injury Assay}

The in vitro scratch wound experiments were performed according to previous studies $(10,21,30)$. Briefly, after flavopiridol was added to the cultures, a $500 \mu \mathrm{m}$ wide cellfree cleft was made by scratching the confluent monolayer from the left wall of the well to the right wall with a sterile $10 \mu \mathrm{l}$ plastic tip. Scratched cultures were examined using a phase contrast microscope (Nikon, Japan), and images were captured at time points $0,3,6$, and $12 \mathrm{~h}$.

\section{Cell Cycle Analysis Using Flow Cytometry}

Astrocytes were cultured in serum-free DMEM media for $24 \mathrm{~h}$ and then treated with $0.5 \mathrm{mM}$ flavopiridol, followed by mitotic stimulation with $10 \%$ FBS for $48 \mathrm{~h}$ (8). Control cells were treated with the same amount of dimethyl sulphoxide (DMSO) instead of flavopiridol. The harvested cells were stained with propidium iodide, and cell cycle analysis was performed with $2 \times 10^{4}$ cells for each experiment using four-laser FACScalibur (BD Biosciences, USA).

\section{Right Spinal Cord Hemisection and Local Delivery of Flavopiridol}

All animal procedures were performed as per the guidelines of the Care and Use of Laboratory Animals and were approved by the Animal Ethical Care and Use Committee of the Second Affiliated Hospital of Nanchang University, Nanchang, China. Female Sprague-Dawley rats $(n=6$ in each group) were purchased from the Chinese Academy of Medical Sciences. The rats were anaesthetised using $10 \%$ chloral hydrate ( $400 \mathrm{mg} / \mathrm{kg}$ body weight). Paravertebral muscles were exposed and dissected by making a longitudinal incision in the midline. Laminectomy was performed according to the protocol described by Ren et al. Briefly, the spinal column was immobilised using a clamp, and a thoracic (T9-T10) dorsal laminectomy was performed using fine rongeurs. Once the spinal cord was exposed, a complete right hemisection was made with fine microdissection scissors at $\mathrm{T} 10$, as described previously $(2,20)$. Flavopiridol solution $(200 \mathrm{mM}, 0.8 \mathrm{nmol}$ flavopiridol/animal), which was prepared fresh immediately before use, was then topically administered to the lesion.

\section{Behavioural Assessment}

We used the BBB (Basso, Beattie, and Bresnahan) locomotor rating scale to evaluate the functional recovery of hind limbs (3). Briefly, the rats were placed in an open field with a pasteboard-covered non-slippery floor. In each testing session, each animal was observed for 4 min by two blinded investigators. The assay was conducted once weekly for 6 weeks after $\mathrm{SCl}$. Sensory motor function was assessed using the grid walking test, which was also conducted once weekly. Animals were placed on an elevated plastic-coated wire mesh 
(40-45 cm with $2 \mathrm{~cm}^{2}$ grid spaces) and were allowed to walk across the platform for $3 \mathrm{~min}$. Paw placement of the hind limbs was tested during the walk. A misstep was scored when the entire foot fell through the grid, and the misstep frequency for the injured limb was calculated.

\section{Statistical Analysis}

The data were statistically analysed using Student's t-test for comparison between two experimental groups. BBB scores were analysed by two-way analysis of variance (ANOVA) and repeated measures. Results were expressed as mean \pm standard deviation and a $P$ value of $<0.05$ was considered as a statistically significant difference.

\section{RESULTS}

\section{Effects of Flavopiridol on Cultured Astrocytes and Neurons}

Using CCK-8 assay, we observed that flavopiridol at a concentrations of $>0.1 \mathrm{mM}$ significantly repressed the proliferation of astrocytes, and at a concentration of $>1 \mathrm{mM}$, it even inhibited the survival of the astrocytes (Figure 1A). Therefore, concentrations between 0.1 and $0.5 \mathrm{mM}$ could be used to inhibit the proliferation of cells without killing them.
After treatment with flavopiridol, the percentage of S-phase astrocytes decreased from $8.3 \%$ to $3.1 \%$. Similarly, there was a decrease in the G2-phase astrocytes from $5.3 \%$ to $2.2 \%$. We also observed a significant reduction in the percentage of scratch wound healing from $51.0 \%$ to $8.1 \%$ at $12 \mathrm{~h}$ after scratch and flavopiridol treatment (Figure 1B). A decrease in the expression of cell cycle-related molecules such as ccnd1 (Figure 1E), along with a decrease in the synthesis of inflammatory factors such as tumour necrosis factor (TNF)-a (Figure 1C) and interleukin (IL)-1b (Figure 1D) and monocyte chemoattractant protein 1 (MCP1), was observed (Figure 1F). Therefore, flavopiridol inhibited the cell cycle, proliferation, scratch wound healing and synthesis of inflammatory factors in astrocytes.

Additionally, we investigated whether flavopiridol affects the survival of neurons, in relation to its effect on the proliferation of astrocytes. We observed that flavopiridol at a concentration of $<0.5 \mathrm{mM}$ did not cause death of neurons (Figure 2A). The data suggest that flavopiridol at concentrations of $0.1-0.5 \mathrm{mM}$ causes the inhibition of astrocytes while protecting neurons. We also found that flavopiridol at a concentration of $0.5 \mathrm{mM}$ downregulated the expression of caspase-3 (Casp3) (Figure

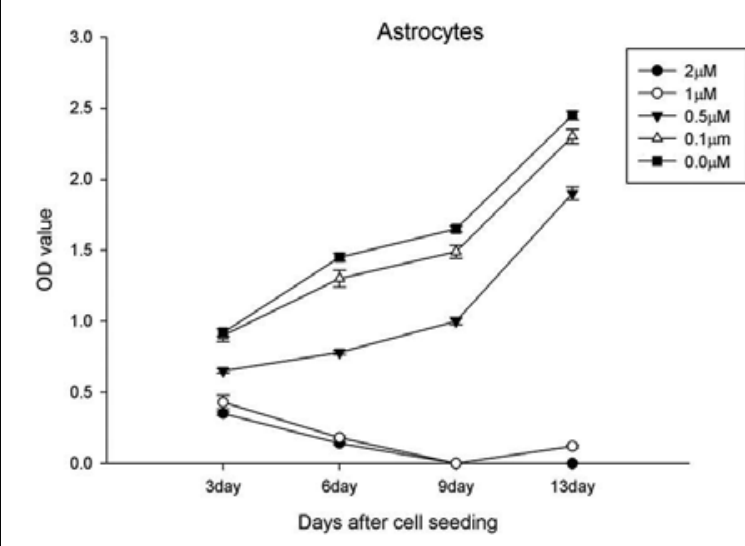

(A)

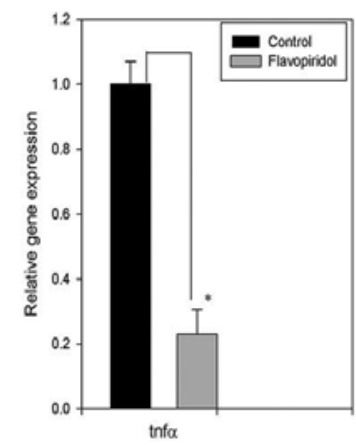

(C)

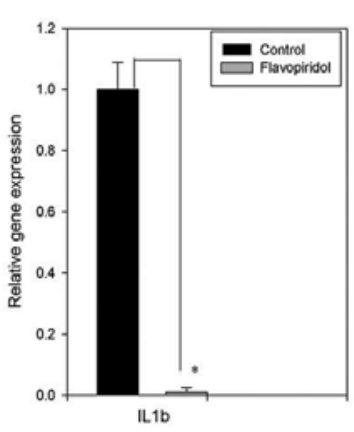

(D)

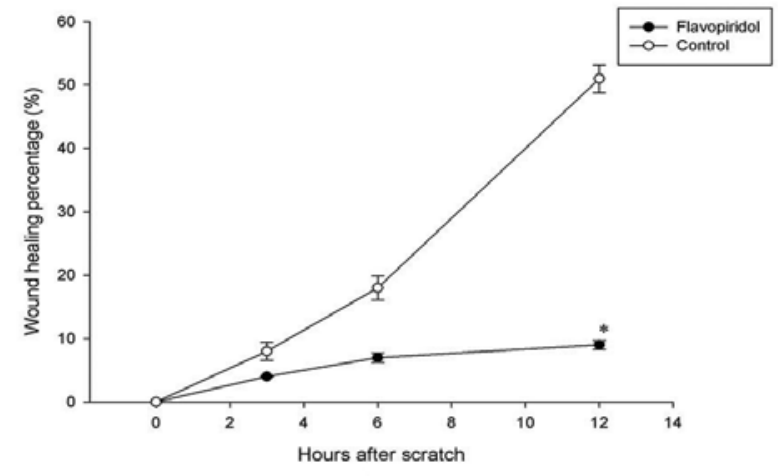

(B)

Figure 1: Impact of flavopiridol on cultured astrocytes. A) Proliferation of astrocytes at different concentrations of flavopiridol. B) Percentage of wound healing. C) Expression analysis of TNF-a. D) Expression analysis of IL1-b. E) Expression analysis of ccnd1. F) Expression analysis of mcp1. Data are mean $\pm \mathrm{SD},{ }^{\star} \mathrm{p}<0.05,{ }^{\star \star} \mathrm{p}<0.01$. 
$2 \mathrm{E})$ but upregulated the expression of neurons (Figure 2B), which may be the cause of neuronal survival. As observed with astrocytes, the expression of molecules related to cell cycle, such as pcna (Figure 2D) and ccnd1 (Figure 2F), was decreased and the expression of CDK inhibitor p27 was increased (Figure 2C). Therefore, flavopiridol was found to inhibit the cell cycle of astrocytes while promoting the survival of neurons.

\section{Structural Recovery of SCI}

The experimental procedure for constructing the righthemisection $\mathrm{SCl}$ model is illustrated in Figure 3A,B. Using $\mathrm{H} \&$ E staining, we observed that $\mathrm{SCl}$ caused a prominent cavity at the site of injury; there was loss of grey and white matter, which was reduced by flavopiridol (Figure 4A-C). The mean cavity area in the longitudinal section of spinal cord decreased to $0.11 \pm 0.10 \mathrm{~mm}^{2}$ in flavopiridol-treated animals as compared to $1.49 \pm 0.62 \mathrm{~mm}^{2}$ in controls. Therefore, intrathecal delivery of flavopiridol in animals with $\mathrm{SCl}$ aids regeneration and survival of neurons and inhibits cavitation and survival of astrocytes.

\section{Evaluation of Inflammation}

Flavopiridol was found to inhibit the inflammatory factors synthesized by astrocytes. Therefore, we investigated whether flavopiridol could inhibit the inflammation in SCl. Delivery of flavopiridol into the injured spinal cord inhibited the cell cycle. Flavopiridol decreased the expression of pcna and significantly decreased the expression of ccnd1. The expression of CDK inhibitor p27 was significantly increased. Flavopiridol administration also caused a significant inhibition of inflammatory factors such as IL-6, TNF- $a$ and IL- $1 b$. There was an increase in the expression of anti-inflammatory factor IL-10. A decreasing trend was observed in the expression of MCP1.

\section{Functional Recovery of $\mathrm{SCl}$}

Functional tests were performed on day 42 after $\mathrm{SCl}$ was induced. Flavopiridol-administered rats showed significantly higher BBB scores $(13.9 \pm 3.1)$ compared with animals treated with the blank solution $(9.1 \pm 4.9)$. Only $20 \%$ of the rats treated with the blank solution could achieve a score $>12$ at day 42 post injury. At day 42, flavopiridol-treated animals also showed improvement in BBB scores (Figure 5A). Functional

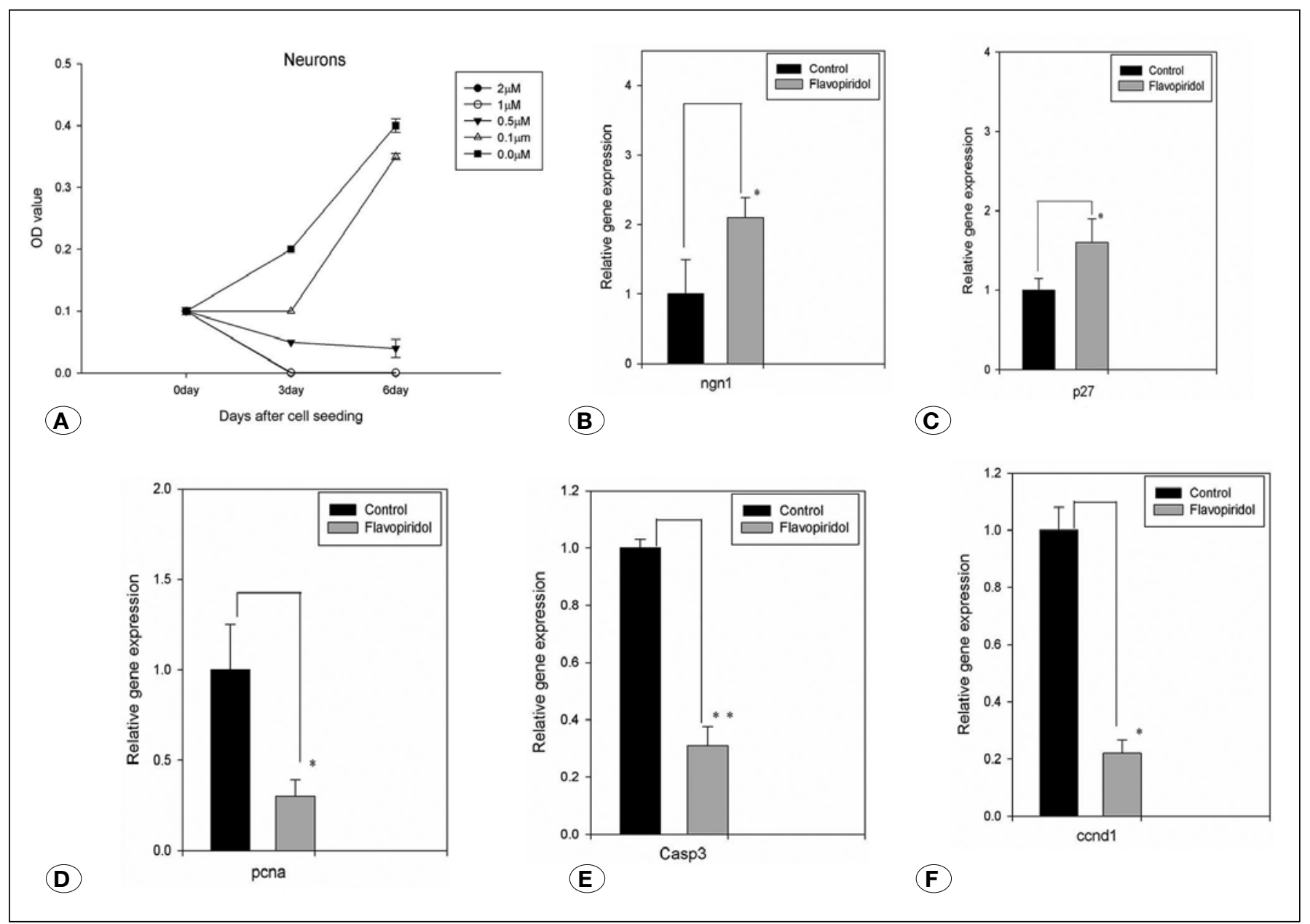

Figure 2: Impact of flavopiridol on cultured neurons. A) Survival of neurons after flavopiridol treatment. B) Expression analysis of ngn1 C) Expression analysis of p27. D) Expression analysis of pcna. E) Expression analysis of Casp3. F) Expression analysis of ccnd1. Data are mean $\pm S D,{ }^{*} p<0.05,{ }^{*} p<0.01$. 

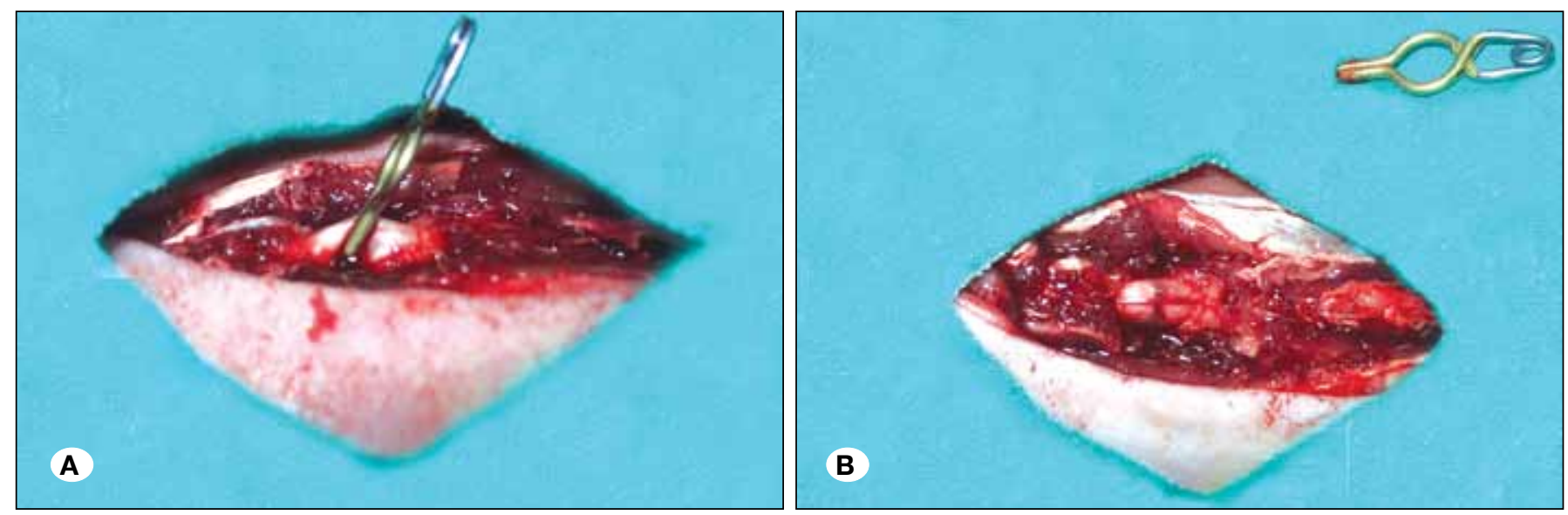

Figure 3: Experimental protocol: Rat spinal cord A) before and B) after injury.

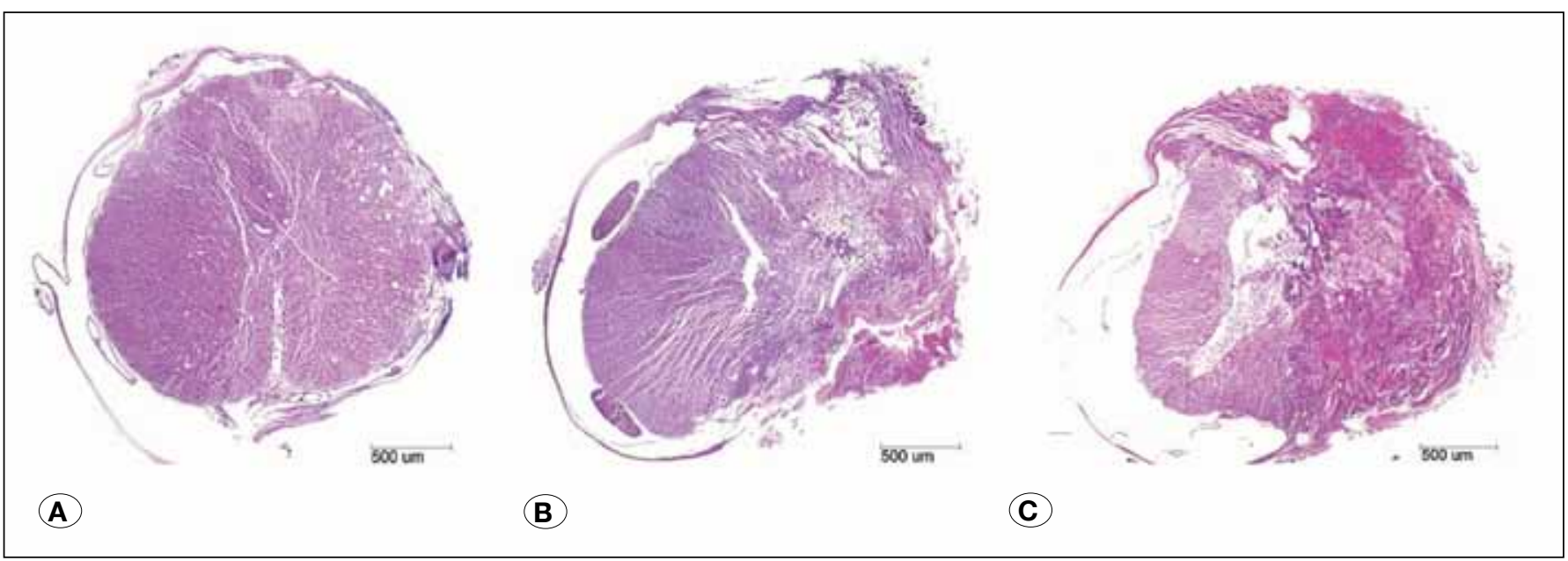

Figure 4: Spinal cord cross sections with H\&E staining A) Spinal cord cross-section showing hemisection injury with approximately $45 \%$ spared tissue remaining B) Spinal cord cross-section showing hemisection injury with approximately $35 \%$ spared tissue remaining C) Spinal cord cross-section showing major hemisection injury.
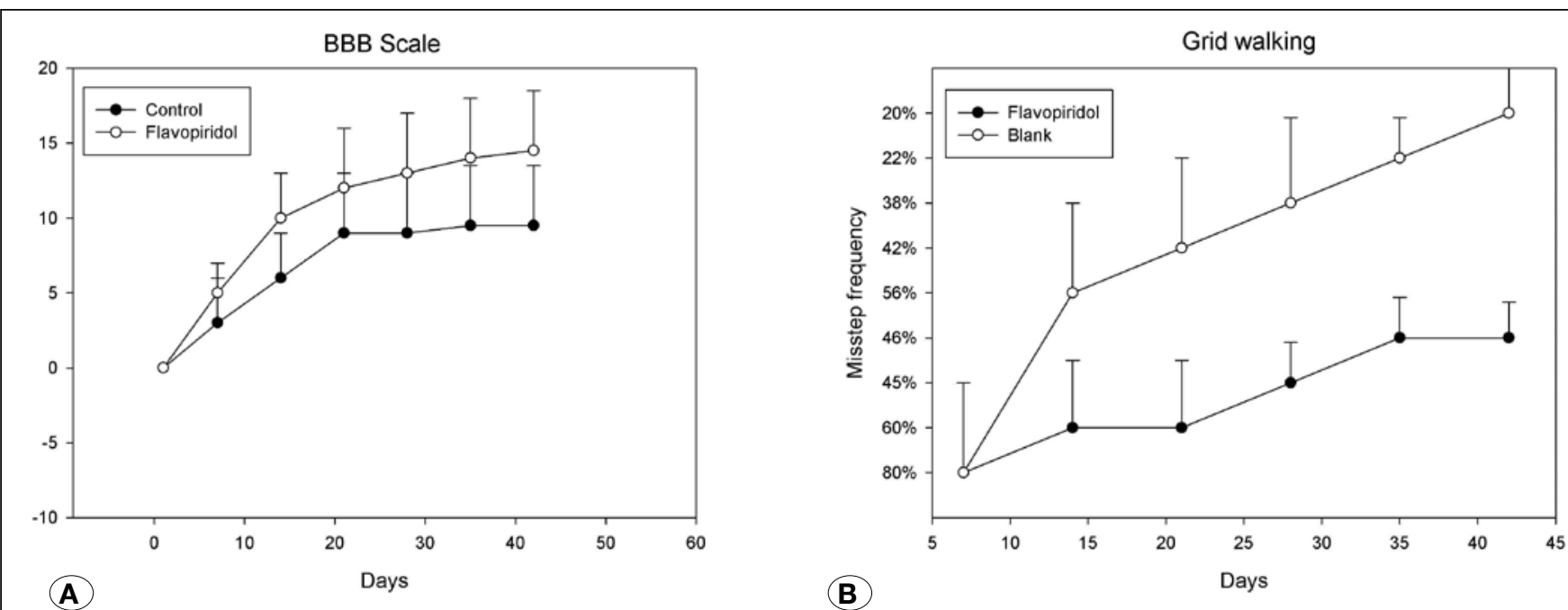

Figure 5: Behavioural performance at different times after SCI. Flavopiridol-treated rats $(n=12)$ had better BBB scores (A) and lower grid walking misstep frequency $(B)$ than blank solution-treated rats $(n=11) 42$ days after injury. Data are mean $\pm S D$. 
improvement was evaluated by grid walking. The percentage of missteps of the hind paws at day 42 post-injury was significantly decreased in the flavopiridol-administered animals than in the animals treated with the blank solution (Figure 5B). On comprehensive analysis, flavopiridol-administered animals showed best outcome of improvement in locomotor function, indicating improvement of motor functions.

\section{DISCUSSION}

The current study shows that intrathecal delivery of flavopiridol improves recovery of $\mathrm{SCl}$ and inhibits the effect on inflammatory factors secreted by astrocytes, both in vitro and in vivo. In animal studies, we found that intrathecal administration of flavopiridol protects the neurons and decreases the scarring of glial cells and cavitation. These findings are consistent with those of previous studies (5, $8,17,39,41,44)$. Flavopiridol repairs $\mathrm{SCl}$ by reducing glial scar formation and limiting neuronal loss $(6,35)$. Moreover, flavopiridol was found to improve sensory motor function, as measured through grid walking $(4,45)$, and directly inhibit the synthesis of inflammatory factors (Figure 1A-F).

It is already known that astrocytes play a significant role in the pathology of neuroinflammation of the central nervous system (CNS) $(9,11,13,34)$. A previous study showed that in primary astrocytes, transcriptional changes in the genes related to cell cycle are caused by inflammatory stimulation (11), suggesting a close relationship between inflammation and cell cycle regulatory proteins; however, the exact mechanism of inflammatory expression in astrocytes by flavopiridol was unclear. In the current study, flavopiridol was also found to inhibit the inflammatory factors synthesized by astrocytes and decrease inflammatory expression in SCl. It may be possible that because of the proteins secreted by astrocytes and the neuroimmune response, there is an increase in capillary permeability and, in turn, an increase in the expression of junctional adhesion molecules and endothelial proteins. These proteins can further cause migration of leukocytes to the $\mathrm{SCl}$ site (43). The migration of leukocytes triggers the release of proinflammatory cytokines IL-1a, IL- $1 \mathrm{~b}$ and TNF- $\mathrm{a}$, which cause apoptotic cell death (28). We also observed that the intrathecal delivery of flavopiridol inhibited the infiltration of macrophages. Therefore, flavopiridol is useful in decreasing inflammation, limiting the loss of neurons loss and promoting the repair of SCl. Flavopiridol was also found to inhibit scratch wound healing (Figure 1A-F). The in vitro scratch injury method is a well-established method used to study cell migration (30). It has been postulated that astrocytes polarize towards the site of scratch wound by forming protrusions prior to migration towards cell-free area (10). In the current study, we also observed that flavopiridol inhibited the expression of cell cycle-related proteins (data not shown).

Flavopiridol is a semisynthetic nonselective inhibitor of CDKs and is naturally obtained from the bark of rohitukin (25). It has been established that flavopiridol arrests cell cycle at G1 or G2/M transition phase (36) and therefore inhibits the proliferation of astrocytes (5).
However, the effect of flavopiridol on neurons was different in the sense that there was a decrease in Casp3 expression (data not shown). Several investigators have shown that flavopiridol reduces the phosphorylation of proteins found in retinoblastoma (5), which then reduces the activation of Casp3 cleavage, E2F transcription factor $(19,33)$ and neuronal apoptosis (26). Studies have also shown that cyclin G1 expression is related to neuronal apoptosis following SCI (7). In this study, we observed an increase in neurogenin 1 (ngn1) expression, which suggests a relationship between cell cycle arrest and ngn1 upregulation (Figure 2B). This is consistent with earlier reports, which have shown that the expression of ngn1 $(12,18)$ can induce cell cycle arrest, which is associated with elevated expression of p27 $(18,29)$. In a study by Piao et al., upregulation of ngn 1 by granulocyte colony stimulating factor (GMCSF) and stem cell factor was found to cause differentiation of neural stem cells (27). Therefore, it is postulated that flavopiridol inhibits the migration and proliferation of astrocytes and promotes the survival of neurons.

\section{- CONCLUSION}

We demonstrated that the local delivery of flavopiridol reduces cavity formation and neuronal loss and improves the regeneration of neurons with improvement in physiological performance. Our results show that this was due to the restriction of glial scarring, improvement in neuronal survival and control of proliferation, migration and inflammatory factors synthesized by astrocytes. Therefore, intrathecal administration of flavopiridol can be a promising treatment strategy in patients with $\mathrm{SCl}$ and needs to be validated in patient setting.

\section{REFERENCES}

1. Ackery A, Tator C, Krassioukov A: A global perspective on spinal cord injury epidemiology. J Neurotrauma 21:13551370, 2004

2. Arvanian VL, Schnell L, Lou L, Golshani R, Hunanyan A, Ghosh A, Pearse DD, Robinson JK, Schwab ME, Fawcett JW, Mendell LM: Chronic spinal hemisection in rats induces a progressive decline in transmission in uninjured fibers to motoneurons. Exp Neurol 216: 471-480, 2009

3. Basso DM, Beattie MS, Bresnahan JC: A sensitive and reliable locomotor rating scale for open field testing in rats. $\mathrm{J}$ Neurotrauma 12: 1-21, 1995

4. Behrmann DL, Bresnahan JC, Beattie MS, Shah BR: Spinal cord injury produced by consistent mechanical displacement of the cord in rats: behavioral and histologic analysis. J Neurotrauma 9: 197-217, 1992

5. Byrnes KR, Stoica BA, Fricke S, Di Giovanni S, Faden Al: Cell cycle activation contributes to post-mitotic cell death and secondary damage after spinal cord injury. Brain 130: 29772992, 2007

6. Davies SJ, Field PM, Raisman G: Regeneration of cut adult axons fails even in the presence of continuous aligned glial pathways. Exp Neurol 142: 203-216, 1996 
7. Di Giovanni S, Knoblach SM, Brandoli C, Aden SA, Hoffman EP, Faden Al: Gene profiling in spinal cord injury shows role of cell cycle in neuronal death. Ann Neurol 53: 454-468, 2003

8. Di Giovanni S, Movsesyan V, Ahmed F, Cernak I, Schinelli S, Stoica B, Faden Al: Cell cycle inhibition provides neuroprotection and reduces glial proliferation and scar formation after traumatic brain injury. Proc Natl Acad Sci USA 102: 8333-8338, 2005

9. Dusaban SS, Purcell NH, Rockenstein E, Masliah E, Cho MK, Smrcka AV, Brown JH: Phospholipase C epsilon links G protein-coupled receptor activation to inflammatory astrocytic responses. Proc Natl Acad Sci USA 110: 3609-3614, 2013

10. Etienne-Manneville $S$ : In vitro assay of primary astrocyte migration as a tool to study Rho GTPase function in cell polarization. Methods Enzymol 406: 565-578, 2006

11. Falsig J, Pörzgen P, Lund S, Schrattenholz A, Leist M: The inflammatory transcriptome of reactive murine astrocytes and implications for their innate immune function. J Neurochem 96: 893-907, 2006

12. Farah MH, Olson JM, Sucic HB, Hume RI, Tapscott SJ, Turner DL: Generation of neurons by transient expression of neural bHLH proteins in mammalian cells. Development 127: 693702,2000

13. Fitch MT, Doller C, Combs CK, Landreth GE, Silver J: Cellular and molecular mechanisms of glial scarring and progressive cavitation: In vivo and in vitro analysis of inflammation-induced secondary injury after CNS trauma. J Neurosci 19: 8182-8198, 1999

14. Gallo V, Armstrong RC: Developmental and growth factorinduced regulation of nestin in oligodendrocyte lineage cells. J Neurosci 15: 394-406, 1995

15. Hellal F, Hurtado A, Ruschel J, Flynn KC, Laskowski CJ, Umlauf M, Kapitein LC, Strikis D, Lemmon V, Bixby J, Hoogenraad CC, Bradke F: Microtubule stabilization reduces scarring and causes axon regeneration after spinal cord injury. Science 331: 928-931, 2011

16. Jäger W, Gehring E, Hagenauer B, Aust S, Senderowicz A, Thalhammer T: Biliary excretion of flavopiridol and its glucuronides in the isolated perfused rat liver: Role of multidrug resistance protein 2 (Mrp2). Life Sci 73: 2841-2854, 2003

17. Kabadi SV, Stoica BA, Byrnes KR, Hanscom M, Loane DJ, Faden Al: Selective CDK inhibitor limits neuroinflammation and progressive neurodegeneration after brain trauma. J Cereb Blood Flow Metab 32: 137-149, 2012

18. Kim YT, Caldwell JM, Bellamkonda RV: Nanoparticle-mediated local delivery of Methylprednisolone after spinal cord injury. Biomaterials 30: 2582-2590, 2009

19. Kitagawa M, Higashi H, Jung HK, Suzuki-Takahashi I, Ikeda M, Tamai K, Kato J, Segawa K, Yoshida E, Nishimura S, Taya Y: The consensus motif for phosphorylation by cyclin D1Cdk4 is different from that for phosphorylation by cyclin A/ECdk2. EMBO J 15: 7060-7069, 1996

20. Liu Y, Wang X, Lu CC, Kerman R, Steward O, Xu XM, Zou Y: Repulsive Wnt signaling inhibits axon regeneration after CNS injury. J Neurosci 28: 8376-8382, 2008
21. Livak KJ, Schmittgen TD: Analysis of relative gene expression data using real-time quantitative PCR and the 2(-Delta Delta C(T)) Method. Methods 25: 402-408, 2001

22. Malumbres M, Barbacid M: Cell cycle, CDKs and cancer: $A$ changing paradigm. Nat Rev Cancer 9: 153-166, 2009

23. Meijer L, Raymond E: Roscovitine and other purines as kinase inhibitors. From starfish oocytes to clinical trials. Acc Chem Res 36: 417-425, 2003

24. Mothe AJ, Tator $\mathrm{CH}$ : Advances in stem cell therapy for spinal cord injury. J Clin Invest 122: 3824-3834, 2012

25. Newcomb EW, Tamasdan C, Entzminger Y, Arena E, Schnee T, Kim M, Crisan D, Lukyanov Y, Miller DC, Zagzag D: Flavopiridol inhibits the growth of GL261 gliomas in vivo: Implications for malignant glioma therapy. Cell Cycle 3: 230-234, 2004.

26. Park DS, Morris EJ, Bremner R, Keramaris E, Padmanabhan J, Rosenbaum M, Shelanski ML, Geller HM, Greene LA: Involvement of retinoblastoma family members and E2F/DP complexes in the death of neurons evoked by DNA damage. $J$ Neurosci 20: 3104-3114, 2000

27. Piao CS, Li B, Zhang LJ, Zhao LR: Stem cell factor and granulocyte colony-stimulating factor promote neuronal lineage commitment of neural stem cells. Differentiation, 83: 17-25, 2012

28. Pineau I, Lacroix S: Proinflammatory cytokine synthesis in the injured mouse spinal cord: Multiphasic expression pattern and identification of the cell types involved. J Comp Neurol 500: 267-285, 2007

29. Polyak K, Lee MH, Erdjument-Bromage $H$, Koff $A$, Roberts JM, Tempst P, Massagué J: Cloning of p27Kip1, a cyclindependent kinase inhibitor and a potential mediator of extracellular antimitogenic signals. Cell 78: 59-66, 1994

30. Robel S, Bardehle S, Lepier A, Brakebusch C, Götz M: Genetic deletion of cdc42 reveals a crucial role for astrocyte recruitment to the injury site in vitro and in vivo. J Neurosci 31: 12471-12482, 2011

31. Rudek MA, Bauer KS Jr, Lush RM III, Stinson SF, Senderowicz AM, Headlee DJ, Arbuck SG, Cox MC, Murgo AJ, Sausville EA, Figg WD: Clinical pharmacology of flavopiridol following a 72-hour continuous infusion. Ann Pharmacother 37: 13691374, 2003

32. Schinelli S, Zanassi P, Paolillo M, Wang H, Feliciello A, Gallo $\checkmark$ : Stimulation of endothelin $B$ receptors in astrocytes induces cAMP response element-binding protein phosphorylation and c-fos expression via multiple mitogen-activated protein kinase signaling pathways. J Neurosci 21: 8842-8853, 2001

33. Sears RC, Nevins JR: Signaling networks that link cell proliferation and cell fate. J Biol Chem 277: 11617-11620, 2002

34. Shao W, Zhang SZ, Tang M, Zhang XH, Zhou Z, Yin YQ, Zhou QB, Huang YY, Liu YJ, Wawrousek E, Chen T, Li SB, Xu M, Zhou JN, Hu G, Zhou JW: Suppression of neuroinflammation by astrocytic dopamine D2 receptors via alphaB-crystallin. Nature 494: 90-94, 2013

35. Silver J, Miller JH: Regeneration beyond the glial scar. Nat Rev Neurosci 5: 146-156, 2004

36. Swanton C: Cell-cycle targeted therapies. Lancet Oncol 5: 2736,2004 
37. Tahirovic S, Hellal F, Neukirchen D, Hindges R, Garvalov BK, Flynn KC, Stradal TE, Chrostek-Grashoff A, Brakebusch C, Bradke F: Rac1 regulates neuronal polarization through the WAVE complex. J Neurosci 30: 6930-6943, 2010

38. Tian DS, Xie MJ, Yu ZY, Zhang Q, Wang YH, Chen B, Chen C, Wang W: Cell cycle inhibition attenuates microglia induced inflammatory response and alleviates neuronal cell death after spinal cord injury in rats. Brain Res 1135: 177-185, 2007

39. Tian DS, Yu ZY, Xie MJ, Bu BT, Witte OW, Wang W: Suppression of astroglial scar formation and enhanced axonal regeneration associated with functional recovery in a spinal cord injury rat model by the cell cycle inhibitor olomoucine. J Neurosci Res 84: 1053-1063, 2006

40. Wang H, Liao Z, Sun X, Shi Q, Huo G, Xie Y, Tang X, Zhi X, Tang Z: Intravenous administration of Honokiol provides neuroprotection and improves functional recovery after traumatic brain injury through cell cycle inhibition. Neuropharmacology 86:9-21, 2014
41. Wang W, Redecker C, Yu ZY, Xie MJ, Tian DS, Zhang L, Bu BT, Witte OW: Rat focal cerebral ischemia induced astrocyte proliferation and delayed neuronal death are attenuated by cyclin-dependent kinase inhibition. J Clin Neurosci 15: 278285, 2008

42. Weber C, Fraemohs L, Dejana E: The role of junctional adhesion molecules in vascular inflammation. Nat Rev Immunol 7: 467477, 2007

43. Wu J, Stoica BA, Dinizo M, Pajoohesh-Ganji A, Piao C, Faden Al: Delayed cell cycle pathway modulation facilitates recovery after spinal cord injury. Cell Cycle 11: 1782-1795, 2012

44. Yin Z, Chen X, Chen JL, Shen WL, Hieu Nguyen TM, Gao L, Ouyang HW: The regulation of tendon stem cell differentiation by the alignment of nanofibers. Biomaterials 31: 2163-2175, 2010

45. Z'Graggen WJ, Metz GA, Kartje GL, Thallmair M, Schwab ME: Functional recovery and enhanced corticofugal plasticity after unilateral pyramidal tract lesion and blockade of myelinassociated neurite growth inhibitors in adult rats. J Neurosci 18: 4744-4757, 1998 